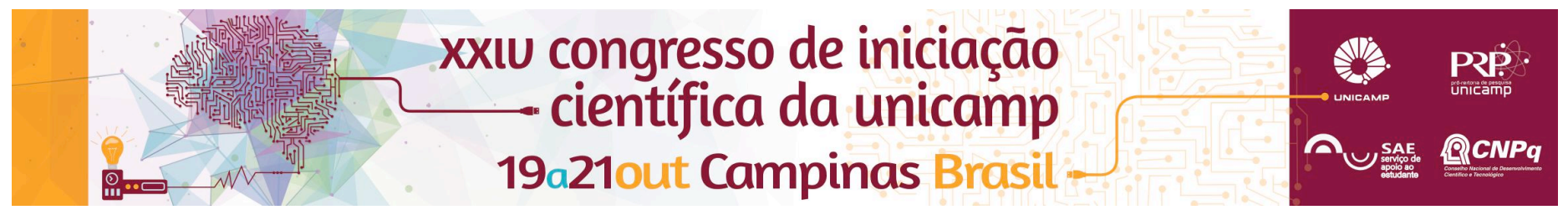

\title{
Avaliação do potencial de adesão de um novo adesivo de técnica úmida de 2 passos.
}

\author{
Livia N. Ferreira (IC)*, Gabriel F. Abuna (PG), Lourenço Correr-Sobrinho (PQ), Mário A. C. Sinhoreti (PQ).
}

\section{Resumo}

O objetivo foi avaliar o potencial de adesão de um novo adesivo comercial comparado com outros que usam a mesma estratégia de adesão. Cinco adesivos dentários comerciais de 2 passos (técnica úmida) foram usados. Foi avaliado o grau de conversão com o espectofotômetro infravermelho transformado de Fourier, com os picos de $1625 \mathrm{~cm}^{-1}$ para a cadeia alifática e $1608 \mathrm{~cm}^{-1}$ para a aromática. 50 dentes molares humanos foram usados para testar a resistência de união, os quais foram restaurados seguindo as recomendações do fabricante e utilizando o compósito Filtek Z350 XT em 3 incrementos de $2 \mathrm{~mm}$. Após, foram obtidos palitos de 0,9 x 0,9 mm para o ensaio de microtração. Os dados foram avaliados com o teste ANOVA (um fator) e as médias comparadas pelo teste Tukey $(p>0.05)$. Os resultados encontrados mostraram que o novo adesivo introduzido no mercado (Ybond Mono) teve resistência de união após 24 horas semelhante ao melhor adesivo comercial (Clearfil SE Bond) e diferente estatisticamente dos outros adesivos. Pode-se concluir que o novo adesivo comercial apresentou ótimo desempenho, quando comparado aos adesivos comerciais.

\section{Palavras-chave}

Adesivos, Adesivos dentinários, Dentina.

\section{Introdução}

A resistência adesiva inicial dos sistemas adesivos aumentou significativamente com a técnica de hibridização da dentina, preconizada por Nakabayashi et al. (1982), devido à formação da denominada camada híbrida, promovendo o selamento da dentina $\mathrm{e}$ diminuindo, assim, os efeitos indesejáveis da microinfiltração marginal (1).

O desenvolvimento técnico-científico dos sistemas adesivos tem ocorrido na busca de maior resistência de união, menor microinfiltração, boa biocompatibilidade, facilidade de técnica e uma adesão efetiva e durável (2). Devido ao aumento de número de adesivos comerciais, cabe perguntar qual é o mais indicado, e se este vai ou não vai ter o sucesso esperado. Assim, foi proposto neste estudo avaliar um novo adesivo de 2 passos com técnica de condicionamento ácido, comparado aos outros adesivos comerciais atualmente utilizados.

\section{Resultados e Discussão}

Os resultados encontrados no presente trabalho mostraram que o novo adesivo introduzido no mercado tem uma resistência de união após 24 horas semelhante ao melhor adesivo comercial avaliado e foi superior estatisticamente aos outros adesivos comerciais.

Figura 1. Resistência de União (MPa)

RESISTÊNCIA DE UNIÃO (MPa)

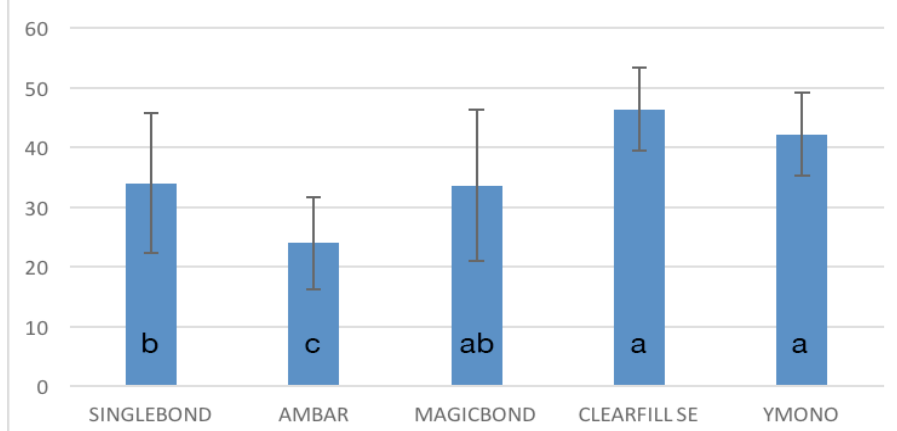

*Letras diferentes significa diferença estatística entre os grupos.
Figura 2. Porcentagem de grau de conversão GRAU DE CONVERSÃO (\%)

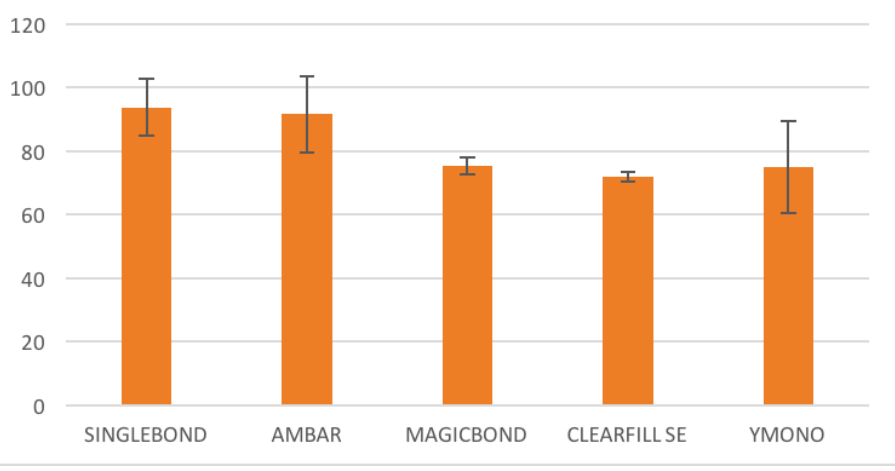

Os dados do grau de conversão do nova adesivo encontram-se dentro dos limites de polimerização de um adesivo dentinário (3).

\section{Conclusões}

Conclui-se que o potencial de adesão do novo adesivo introduzido no mercado se encontra igual ou acima dos atualmente disponíveis (resistência de união) e com um grau de conversão aceitável quando comparado com todos os outros adesivos.

\section{Agradecimentos}

\section{CNPq e ao Laboratório de Biomateriais da UNG.}

\footnotetext{
1. Nakabayashi N. Bonding mechanism of resins and the tooth. Kokubyo Gakkai Zasshi. 1982 Jun;49(2):410.

2. Peumans M, Kanumilli P, De Munck J, Van Landuyt K, Lambrechts P, Van Meerbeek B. Clinical effectiveness of contemporary adhesives: a systematic review of current clinical trials. Dental materials 2005 Sep;21(9):864-81.

3. Navarra CO, Breschi L, Turco G, Diolosà M, Fontanive L, Manzoli L, et al. Degree of conversion of two-step etch-and-rinse adhesives: In situ microRaman analysis. Journal of dentistry. 2012 Sep;40(9):711-7.
} 